\section{The Greatest Show on Earth!}

In June, I, like thousands of my colleagues, made my annual trip to Chicago to attend the ASCO annual meeting. It's the largest meeting in the world of its kind, serving oncology professionals from all sectors. It brings together oncology providers of all stripes who want to learn how to improve care for patients. But it also attracts stakeholders in cancer drug development: patients and advocates looking for hope, industry scientists and staff working to bring new drugs to market, regulators interested in safety and efficacy, and investors looking for opportunities. It makes for a rich fabric, indeed!

I've been going to this meeting for more than 30 years and have watched it grow in size and complexity. Concurrent sessions make it difficult to attend everything, and frankly you must have a lot of discipline to attend what you need to without being distracted by other tantalizing topics. Presentations range from first reports of clinical trials in all phases to educational sessions that tackle every possible topic related to screening, prevention, and treatment, including symptom management across the spectrum, from cancer therapy through survivorship.

But I was really struck this year by how the conversations have changed and how new concepts have emerged. For instance, drugs today are virtually all "designer drugs" synthesized to address select targets within the cancer or the tumor microenvironment. This is the essence of "precision medicine." By necessity, this means that we are reclassifying cancers using genomic or other analytic measures and acting on that information in management decisions. It's no longer adequate in most cancers to use classic clinicopathologic features. And it seems that the more we know, the more we need to learn.

Another conversation that has emerged revolves around "value," a topic I've written on before. Estimating "value" depends on context. We can argue about how we might derive estimates of value, but when it comes to new clinical interventions, especially new drugs, we are clearly seeking a big impact. Wisely, for the most part, randomized trials are being launched quickly, but only if there is a strong signal for success. Planning for big impact (think hazard ratio of at least 0.75 ) allows for smaller sample sizes and more efficient use of resources.

Over time, as treatments improve, the prevalence of people living with cancer or past cancer continues to grow. Thus, the concept of survivorship has percolated through virtually all cancer types. Historically, this conversation was held primarily in the context of pediatric cancers. Today, we recognize that the supportive care we provide to patients throughout their journey is just as critical as the treatment that controls or eradicates their disease.

At this year's meeting, one of the highlights was a visit from Vice President Joe Biden to discuss the new Cancer Moonshot Initiative. He emphasized 2 more conversations. One was immunotherapy. In the past, this was a conversation that occurred in small rooms attended by selected cognoscenti. Today, immunotherapy has arrived as an important new addition to our treatment toolbox in most malignancies. Many new strategies are currently in testing. Vice President Biden also spoke of collaboration and team science and sharing data, particularly big data. Collaboration has always been part of the conversation, but it existed more as an option than a necessity.

These new developments are refreshing to me. I think our community has reached a new level of sophistication in patient care and related research. I also think we know what direction we need to take and which hill we need to climb next. As the conversation evolves, so does our progress. Believe me, the best is yet to come!

What do you think? Please e-mail correspondence (include contact information) to JNCCN@nccn.org.

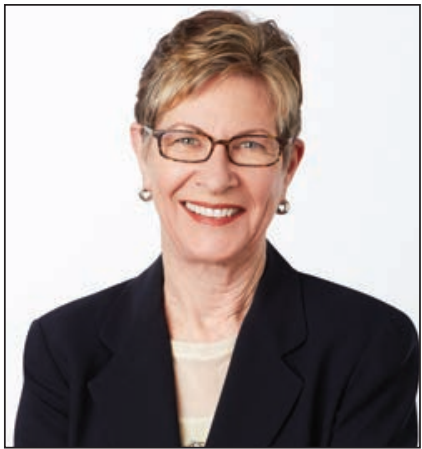

Margaret Tempero, MD

Margaret Tempero, MD, is a Professor of Medicine and Director of the UCSF Pancreas Center and editor-in-chief of JNCCN. Her research career has focused on pancreatic ductal adenocarcinoma, especially in the area of investigational therapeutics. Dr. Tempero has served on the ASCO Board of Directors and as ASCO President. She currently serves on the ASCO Conquer Cancer Foundation Board. She codirected the AACR/ASCO Methods in Clinical Cancer Research and taught this course and similar courses in Europe and Australia. She was founding Chair of the $\mathrm{NCl}$ Clinical Oncology Study Section and served as a member and Chair of the NCl Board of Scientific Counselors Subcommittee $A$. She is a member of the Scientific Steering Committee and Chair of the Clinical and Translational Study Section for the Cancer Prevention \& Research Institute of Texas. She is or has been on the Scientific Advisory Boards of the Lustgarten Foundation, the Pancreatic Cancer Action Network, the $V$ Foundation, The Alberta Canada Cancer Board, and the EORTC. She served as a member of the Oncology Drug Advisory Committee for the FDA. She has served as Deputy Director and Interim Director for the UNMC Eppley Cancer Center. She is Chief Emeritus of the Division of Medical Oncology at UCSF and served as the founding Deputy Director and Director of Research Programs at the UCSF Helen Diller Family Comprehensive Cancer Center.

The ideas and viewpoints expressed in this editorial are those of the author and do not necessarily represent any policy, position, or program of NCCN. 